\title{
Modelling and Analysis of Step Response Test for Hydraulic Automatic Gauge Control
}

\author{
Yi Jiangang* \\ 1 Jianghan University, Hubei Key Laboratory of Industrial Fume \& Dust Pollution Control, China
}

The step response for hydraulic automatic gauge control (HAGC) determines the steel rolling speed and the steel sheet thickness in the process of rolling production. In this paper, the step response test process of HAGC was analysed, and a test approach was proposed for it. Based on that, the transfer function model of the step response test was established and simulated by using Matlab. In order to reduce the settling time and the overshoot, an adaptive proportional-integral-derivative (APID) link was presented in order to compensate for the input signal by using back propagation neural networks (BPNN). The experimental results show that the improved step response test model reaches the process requirements of HAGC, eliminates the jitter of the HAGC system at the start-up phase, and has better stability as well as faster response for steel sheet rolling.

Keywords: step response, hydraulic automatic gauge control, proportional-integral-derived controller, artificial neural networks

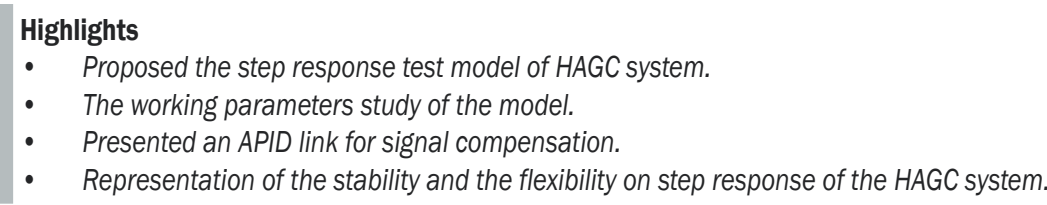

\section{O INTRODUCTION}

Sheet gauge is one of the main quality indicators for steel sheet in the process of rolling production. To improve the control precision of sheet gauge, hydraulic automatic gauge control (HAGC) is currently widely used. In the process of HAGC, the step response plays the most important role, because it determines the steel rolling speed and the steel sheet thickness, and accordingly influences steel sheet surface quality. The step response test is a time-domain test method for system dynamic characteristics. It is used to describe the dynamic response process of the control system when the input is a step signal. To achieve uniform thickness of a steel sheet, the step response parameters of the HAGC should be adjusted according to the real-time thickness of steel sheet. However, during the step response process of HAGC, the step response parameters are influenced by the interactions of hydraulic cylinders, servo valves, and various sensors of the system, and the working time is extremely short (no more than 1 second). Consequently, it is of vital importance to model, test, and analyse the step response of HAGC.

In terms of HAGC system design, Wang et al. and Taleb et al. developed a real-time simulator for a hotrolling mill based on a digital signal processor, which can be used for controlling the hydraulic cylinder in an HAGC system [1] and [2]. Gao et al. proposed a simulated model of $1100 \mathrm{~mm}$ rolling mill HAGC system by using position-pressure compound control method [3]. T.S. Tsay presented a command tracking error square control scheme, and designed feedback control systems [4]. To achieve good control effect, many researchers studied the control algorithm of HAGC. Ang et al. and Mitsantisuk et al. researched the general design method of control system with proportional-integral-derived controller (PID) [5] and [6]. Zhang et al., Dou et al. and Chang et al. analysed the PID parameters setting problem [7] to [9]. Their research proved that the PID controller with proper parameters was efficient, but the setting of the PID parameters is the main problem. To achieve the desired strip thickness of the HAGC system, Khosraviet al. and Song et al. proposed a novel fuzzy adaptive PID controller [10] and [11]. The simulation results showed that it was better than traditional PID controller, but sensitive to parameter variations. Wan et al. and Kasprzyczak et al. analysed the main parameters of the hydraulic system and discussed their effects on system stability [12] to [13].

To solve the problem of multivariable parameters adjustment of the PID controller, several authors proposed some intelligent algorithms, such as evolutionary algorithms, particle swarm optimization (PSO), artificial neural networks (ANN) and generalized predictive control method [14] to [18]. The results indicated the intelligent algorithms improved the adaptability of the PID controller. However, the dynamic response process of the controller under step- 
input was not discussed. In the literature, the research put emphasis on the design, analysis and control of HAGC, and few papers studied the step response test of HAGC.

In this paper, the step response test of HAGC is analysed, a test approach is proposed, and a transfer function model of the step response test is established and simulated by using Matlab software. In order to reduce the settling time and the overshoot, an adaptive proportional-integral-derivative (APID) link is presented to compensate for input signal by using back propagation neural networks (BPNN). The experimental results show that the improved step response test model reaches the process requirements of HAGC, eliminates the jitter of the HAGC system at the start-up phase, and has better stability as well as a faster response for steel sheet rolling.

The structure of this paper is organized as follows. Section 1 introduces the parameters and the approach of the step response test of HAGC. Section 2 establishes the step response test model with transfer function. Section 3 simulates the proposed model by using Matlab, and presents the improved model of the step response test by adding an APID link based on BPNN. Section 4 contains the experiments and the analysis of the improved model. Section 5 is devoted to the conclusions.

\section{THE STEP RESPONSE TEST OF HAGC}

\subsection{The Parameters of the Step Response Test}

In Fig. 1, the $x$ coordinate value of the response signal curve represents the step response time, and the $y$ coordinate value represents the displacement of the piston rod in the HAGC system. Next, the parameters of the step response test include the rise time $t_{r}$, the maximum overshoot $M_{p}$, and the settling time $t_{s}$. The rise time $t_{r}$ is the time at which the response signal reaches the first steady-state output, as described in Eq. (1):

$$
t_{r}=t_{0.9}-t_{0.1},
$$

where $t_{0.9}$ is the time at which the response signal is $90 \%$ of the first steady-state output, and $t_{0.1}$ is the time at which the response signal is $10 \%$ of the first steadystate output.

The difference between the response signal and steady-state output functions as the numerator, and the steady-state output as the denominator, the overshoot as the ratio of them. Next, the maximum overshoot $M_{p}$ can be calculated by Eq. (2):

$$
M_{\mathrm{P}}=\frac{x_{o}\left(t_{p}\right)-x_{o}(\infty)}{x_{o}(\infty)} \times 100 \%,
$$

where $x_{\mathrm{o}}(t)$ is the displacement of the piston rod at the time $t$, and $t_{p}$ is the time at which the response signal reaches the peak.

In the step response process, the settling time $t_{\mathrm{s}}$ is also called the transition time, which represents the time at which the HAGC system reaches the steadystate. It is defined as the time at which the value of $x_{\mathrm{o}}(t)$ satisfies Eq. (3):

$$
\left|x_{\mathrm{o}}(t)-x_{\mathrm{o}}(\infty)\right| \leq 0.05 x_{\mathrm{o}}(\infty) \text {. }
$$

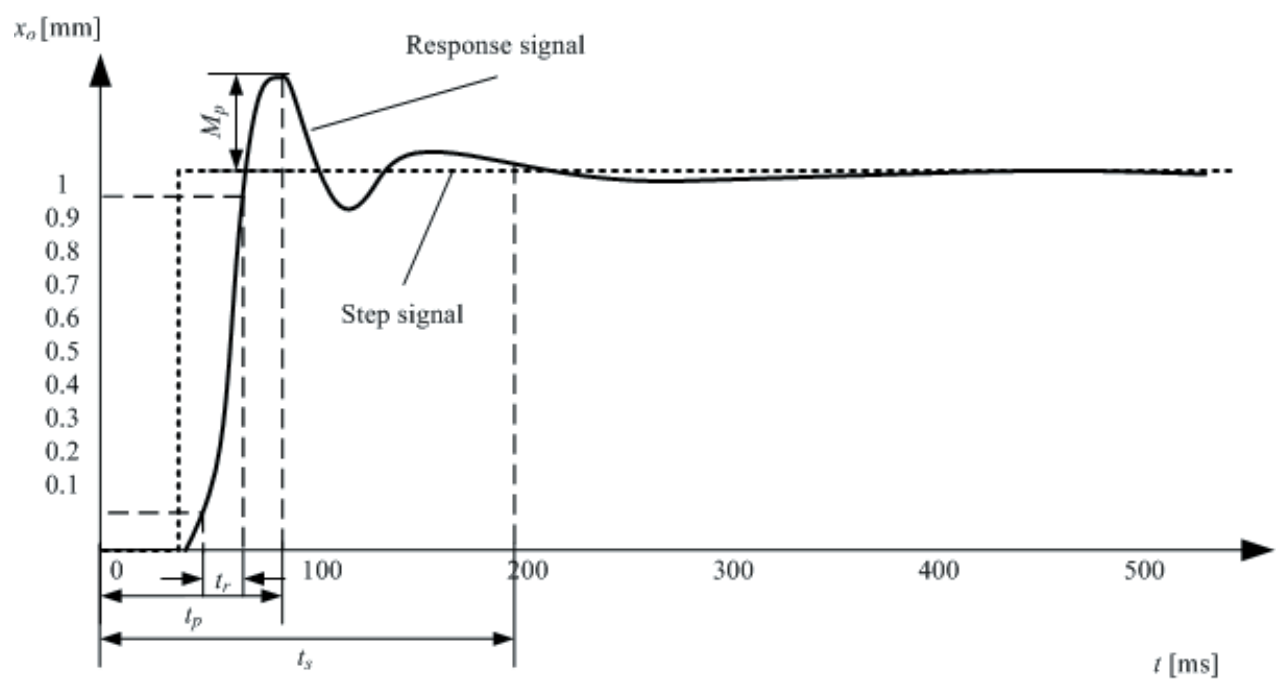

Fig. 1. The parameters of the step response test 
In the parameters of the step response, the settling time $t_{\mathrm{s}}$ reflects the flexibility of the HAGC system, and the maximum overshoot $M_{p}$ reflects the stability of HAGC system. In an HAGC system, it is always considered that the shorter of $t_{s}$ and $M_{p}$, the better of the control effect.

\subsection{The Approach of the Step Response Test}

The main components in the step response process of HAGC are the servo valve, mill cylinder, current sensors, and displacement sensors. In order to simplify the test process, the influence of the hydraulic pipe and hydraulic power components is neglected. Next the approach of the step response test is shown in Fig. 2, and the main test steps are as follows:

Step 1: The displacement of step signal is given to the computer test software. It is converted to a voltage signal by the data acquisition card and is sent to the current sensor (6).

Step 2: The output signal of the data acquisition card is converted to current by the current sensor (6), and then is sent to the servo valve (5) to control the output flow in valve port $\mathrm{A}$.

Step 3: According to the output flow in the valve port A, the piston rod (3) of mill cylinder 2 moves updown to control the rolling thickness of steel sheet.

Step 4: The real-time displacement of the rolling thickness is measured by the displacement sensor (4), and then is converted to digital signal by the data acquisition card.

Step 5: The acquired digital signal is sent to the computer test software, which will be compared with the input displacement in Step 1 to determine the next input value.

\section{MODELLING OF THE STEP RESPONSE TEST}

\subsection{The Parameters of the Step Response Test}

According to Fig. 2, the step response test scheme is established, as shown in Fig. 3. The input signal $U_{v}$ is the step signal of the expected displacement. The output signal $Y_{p}$ is the real-time displacement of the mill cylinder, which is converted to the voltage signal $U_{p}$ by the displacement sensor and fed back to the input port of the servo valve. The difference between $U_{v}$ and $U_{p}, U_{e}$, is converted to the current signal by the current sensor and is used to drive the servo valve. The piston rod action of the mill cylinder is controlled by the output flow of the servo valve.

If the PID link is neglected and the input signals are sent to drive the servo valve directly, the transfer function of the servo valve is:

$$
G_{1}(s)=\frac{K_{s v}}{\frac{s^{2}}{\omega_{s v}^{2}}+\frac{2 \xi_{s v}}{\omega_{s v}} s+1},
$$

where $K_{S v}$ is the output flow gain of the servo valve, $\omega_{s v}$ is the natural frequency of the servo valve, and $\xi_{s v}$ is the damping radio of the servo valve.

The transfer function of the mill cylinder is:

$$
G_{2}(s)=\frac{\frac{A_{c}}{K K_{c e}}}{\left(\frac{s}{\omega_{r}}+1\right)\left(\frac{s^{2}}{\omega_{h}^{2}}+\frac{2 \xi_{h}}{\omega_{h}} s+1\right)},
$$

where $\omega_{r}$ is the transition frequency of the inertia, and $\omega_{h}$ and $\xi_{h}$ are the natural frequency and the damping radio of the mill cylinder. $K_{c e}$ is the overall flowpressure coefficient, $K$ is the load stiffness, and $A_{c}$ is the effective area of the piston rod of the mill cylinder.

The transfer function of the current sensor is:

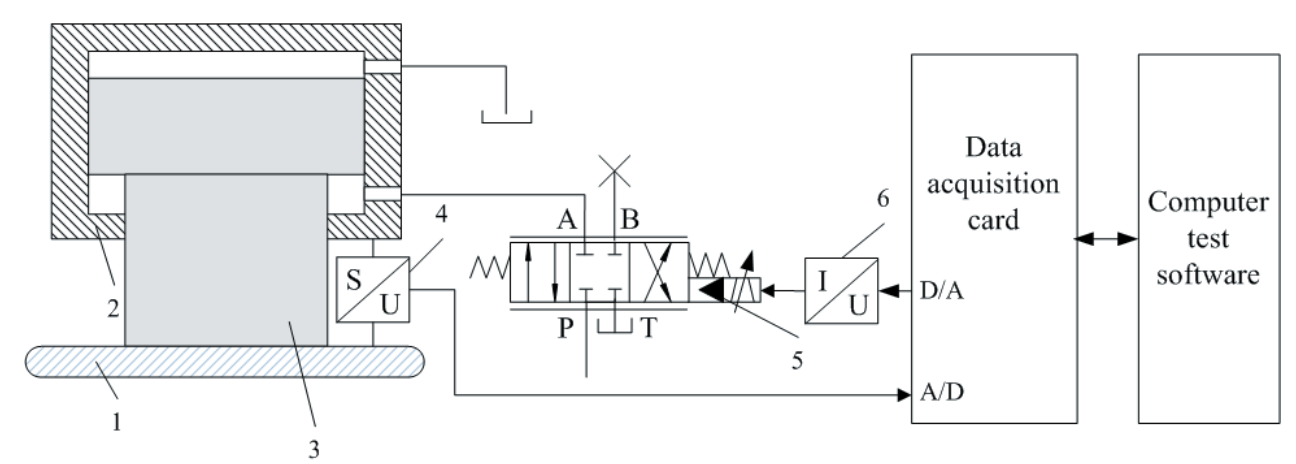

Fig. 2. The step response test of HAGC; 1-Steel sheet, 2-Mill cylinder, 3-Piston rod, 4-Displacement sensor, 5-Servo valve, 6-Current sensor 


$$
G_{3}(s)=K_{i}
$$

where $K_{i}$ is the gain of current.

The transfer function of the displacement sensor is:

$$
H(s)=K_{s},
$$

where $K_{s}$ is the feedback coefficient of displacement.

\subsection{Adding PID Link}

To reduce the settling time and the maximum overshoot of HAGC, some researchers proposed compensating for the input signal by using some algorithms. The signal compensation is implemented by adding a new link to improve the system performance. Because the PID algorithm is flexible, and its parameters can be easily adjusted, it is widely used in control systems. Therefore, based on the step response test scheme, a PID link is added in the step response test scheme between the input signal $U_{e}$ and the current sensor, as shown in Fig. 3.

The PID algorithm includes a proportional part, an integral part, and a differential part. Consequently, three coefficients, $K_{p}, T_{i}$ and $T_{d}$, are used in PID controller for the system control, where $K_{p}$ is the proportional coefficient, $T_{i}$ is the integral coefficient, and $T_{d}$ is the derivative coefficient. Therefore, the conventional PID algorithm can be described as:

$$
G_{4}(s)=\frac{U_{g}}{U_{e}}=K_{p}+\frac{1}{T_{i} s}+T_{d} s .
$$

In terms of Fig. 3 and Eqs. (4) to (8), the overall transfer function model of the step response test with conventional PID algorithm can be described as Eq. (9):

$$
\begin{aligned}
G(s) H(s)= & \frac{K_{s v}}{\frac{s^{2}}{\omega_{s v}^{2}}+\frac{2 \xi_{s v}}{\omega_{s v}} s+1} \cdot \frac{\frac{A_{c}}{K K_{c e}}}{\left(\frac{s}{\omega_{r}}+1\right)\left(\frac{s^{2}}{\omega_{h}^{2}}+\frac{2 \xi_{h}}{\omega_{h}} s+1\right)} . \\
& \cdot K_{i} K_{s} \cdot\left(K_{p}+\frac{1}{T_{i} s}+T_{d} s\right) .
\end{aligned}
$$

\section{SIMULATION AND IMPROVEMENT OF THE STEP RESPONSE TEST}

\subsection{Simulation of the Step Response Test}

To analyse the control effect with and without a PID link in the step response test, the working parameters are loaded to the established transfer function model in the HAGC system, and the step response test is simulated by using the Simulink toolbox in Matlab software. The simulated model with the working parameters is shown in Fig. 4. In the simulated model, a step signal of $1 \mathrm{~mm}$ displacement is loaded at the input point, and the output result is shown as the blue dot curve in Fig. 5. In Fig. 5, it can be observed that $t_{s}=140 \mathrm{~ms}, M_{p}=25 \%$. However, in the HAGC production process, it is necessary that $t_{s}<100 \mathrm{~ms}$ and $M_{p}<10 \%$ for steel sheet rolling. Therefore, the settling time and the maximum overshoot are beyond the range of the HAGC requirements, which means the step response test without a PID link cannot be used to drive the HAGC system directly.

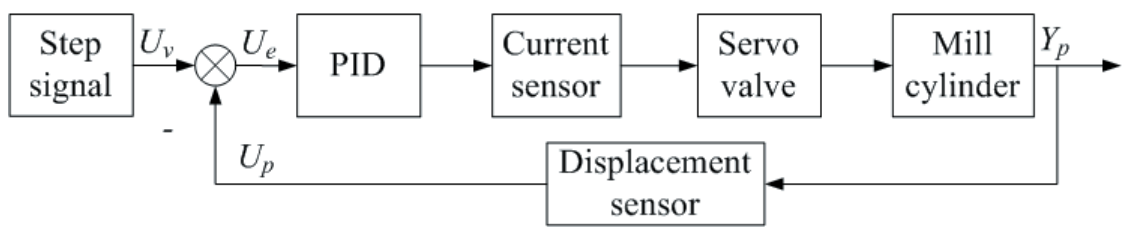

Fig. 3. The step response test scheme

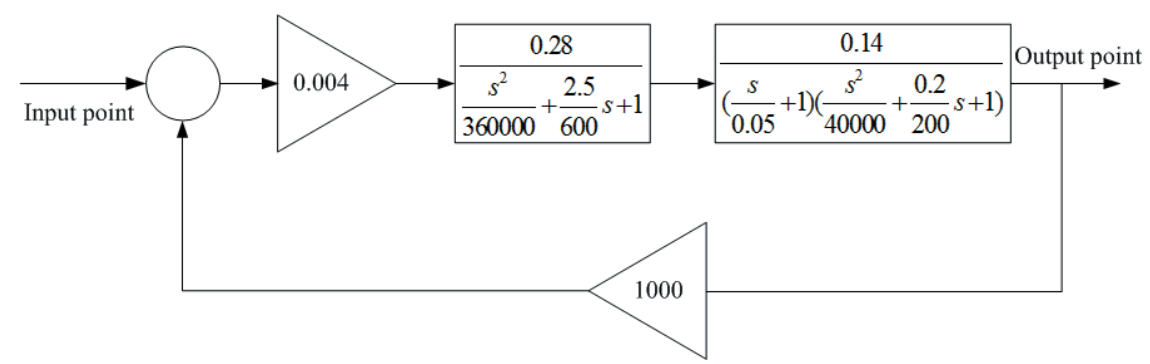

Fig. 4. The simulated model with working parameters 


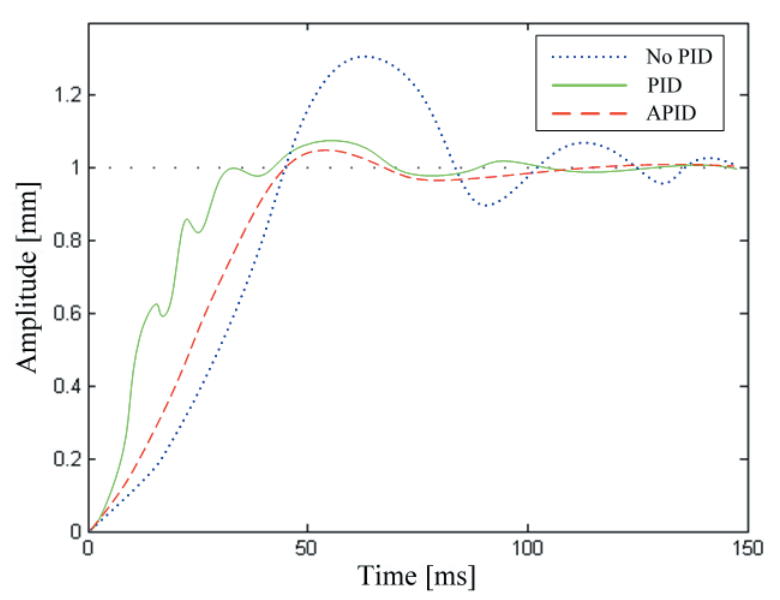

Fig. 5. The simulated results of the step response test

By adding the PID link in the established model in Fig. 4, the step response test is simulated with a conventional PID algorithm, and the output result is shown as a green solid curve in Fig. 5. It is found when $K_{p}=10, T_{i}=50$, and $T_{d}=0$, the settling time $t_{s}=80 \mathrm{~ms}$, and the maximum overshoot $M_{p}=9 \%$, which meet the process requirements of the HAGC. Moreover, testing shows that increasing $K_{p}$ and $T_{d}$, and decreasing $T_{i}$ can further reduce the values of $t_{s}$ and $M_{p}$. However, at the same time, it leads to large jitters in the rise time of the step response test, which impairs the stability of the HAGC system.

\subsection{Improvement of the Step Response Test}

The simulation results of the model with a PID link indicate that the contradiction between the stability and flexibility of the HAGC system cannot be solved by the conventional PID algorithm. This is because the PID parameters of the conventional PID algorithm are constant during the process of the step response test, which cannot be adjusted according to the input and output signals adaptively. In the actual production of steel sheet, because of the interactions of the servo valve, mill cylinder, and sensors in the HAGC system, the step response is a nonlinear time-varying process.

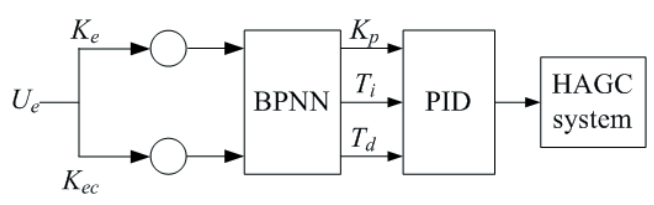

Fig. 6. The structure of the APID for HAGC system

As a result, an APID algorithm based on BPNN is proposed. The structure of the APID algorithm is shown in Fig. 6. The error $K_{e}$ and the error change rate $K_{e c}$ of $U_{e}$ as the input values of the ANN, and $K_{p}$, $T_{i}$ and $T_{d}$ as the output values, the BPNN is used to calculate the proper PID parameters by training it with acquired samples.

\subsection{Implementation of APID}

In recent years, many ANN algorithms have become widely used in both academic research and industrial development. In all ANN algorithms, BPNN is a multilayer forward-spread network with a minimum mean square deviation learning method. It has been proved that BPNN can map all nonlinear functions with single layers. Therefore, a BPNN is created by using the Neural Networks toolbox in Matlab to implement the APID link of HAGC system. The BPNN is composed of an input layer with 2 neurons $\left(K_{e}\right.$ and $\left.K_{e c}\right)$, a hidden layer with 4 neurons (set in the neural networks toolbox) and an output layer with 3 neurons $\left(K_{p}, T_{i}\right.$ and $\left.T_{d}\right)$. The training function is TRAINLM, the adaption learning function is LEARNGDM, and the transfer function is LOGSIG. The samples are collected from the steel sheet production of HAGC system. Table 1 lists 10 sets of the normalized data which are used as the training samples for the built BPNN.

Table 1. The training samples of the BPNN

\begin{tabular}{cccccc}
\hline Number & $K_{e}$ & $K_{e c}$ & $K_{p}$ & $T_{i}$ & $T_{d}$ \\
\hline 1 & 0.442 & 0.193 & 0.056 & 0.071 & 0.010 \\
\hline 2 & 0.095 & 0.794 & 0.150 & 0.076 & 0.093 \\
\hline 3 & 0.119 & 0.101 & 0.097 & 0.070 & 0.105 \\
\hline 4 & 0.094 & 0.099 & 0.620 & 0.588 & 0.197 \\
\hline 5 & 0.893 & 0.545 & 0.212 & 0.092 & 0.081 \\
\hline 6 & 0.792 & 0.152 & 0.078 & 0.063 & 0.098 \\
\hline 7 & 0.541 & 0.085 & 0.038 & 0.041 & 0.033 \\
\hline 8 & 0.113 & 0.125 & 0.255 & 0.119 & 0.100 \\
\hline 9 & 0.867 & 0.048 & 0.243 & 0.008 & 0.025 \\
\hline 10 & 0.133 & 0.020 & 0.135 & 0.009 & 0.011 \\
\hline
\end{tabular}

The ability of ANN is generally measured by its mean-squared error (MSE). With the collected data in Table 1, the built BPNN is trained, and the change of the MSE is shown in Fig. 7. It can be seen when the training MSE goal is 0.01 ; the training times are no more than 500, which indicates that the proposed BPNN is convergent for APID control.

After the BPNN is trained, it can be used to calculate the APID parameters with current values of $K_{e}$ and $K_{e c}$. The step response test of HAGC with the APID controller is simulated again by inputting the same values in the conventional PID controller ( $\left.K_{e}=0.326, K_{e c}=0.247\right)$, and the result is shown as the red dashed curve in Fig. 5. In comparing the green 
solid curve (PID) and the red dash curve (APID), it is obvious that by using the APID algorithm, the step response can not only reach the process requirements of the HAGC, but also eliminate the jitter at the startup phase, which means the HAGC system has better stability and flexibility with the improved model.

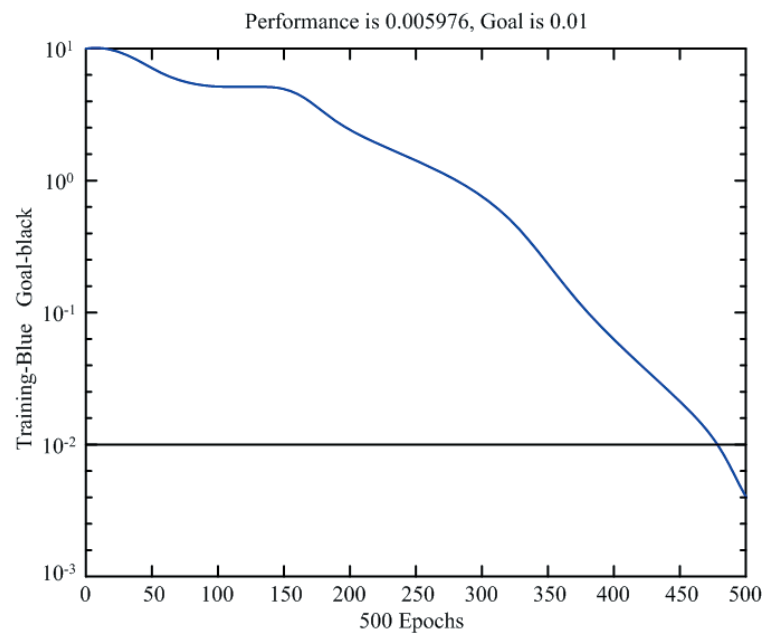

Fig. 7. The training result of the BPNN

\section{EXPERIMENTAL RESULTS}

In order to verify the established step response test model in Section 2 and Section 3, experiments were done with the designed HAGC system of the mill servo cylinder, as shown in Fig. 8. The type of the mill cylinder is C1450-P20N000, the piston rod diameter is $1450 \mathrm{~mm}$, and the stroke length is $10 \mathrm{~mm}$. The embedded computer servo controller receives the acquired signals from the sensors and the servo valves, and sends the calculated results to the HAGC system. The APID algorithm is programmed with Visual C++ and loaded into the HAGC controller. To test step response ability of the HAGC system, the standard step input signals were sent through the HAGC controller, as shown in Fig. 9a. The step response models without PID link, with conventional PID link and with APID link were tested, and the experimental results were shown on the HAGC controller screen, as shown in Fig. 9b. By comparing Fig. 5 and Fig. $9 \mathrm{~b}$, it can be determined that there is good agreement between the simulated and the experimental results.

By using the APID algorithm and conventional PID algorithm, the change of the steel sheet thickness within $100 \mathrm{~ms}$ is measured, as shown in Fig. 10. It can be seen that the thickness change in the step response test of HAGC with APID is no more than $0.06 \mathrm{~mm}$, and the surface irregularity has a decreased trend as

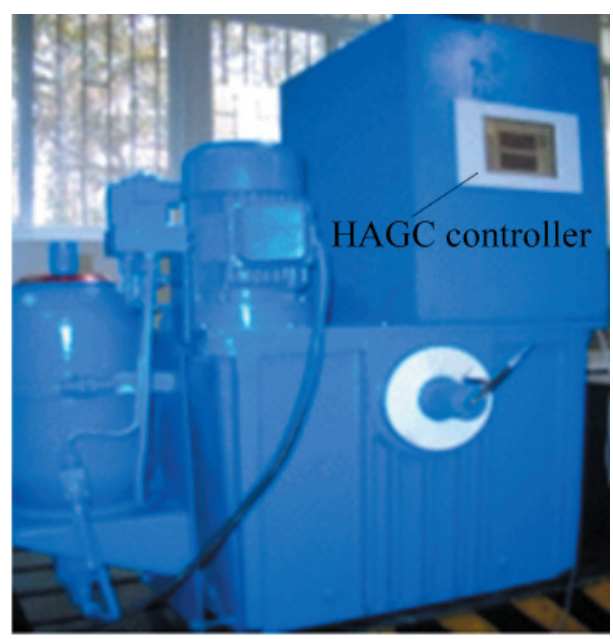

Fig. 8. The HAGC system
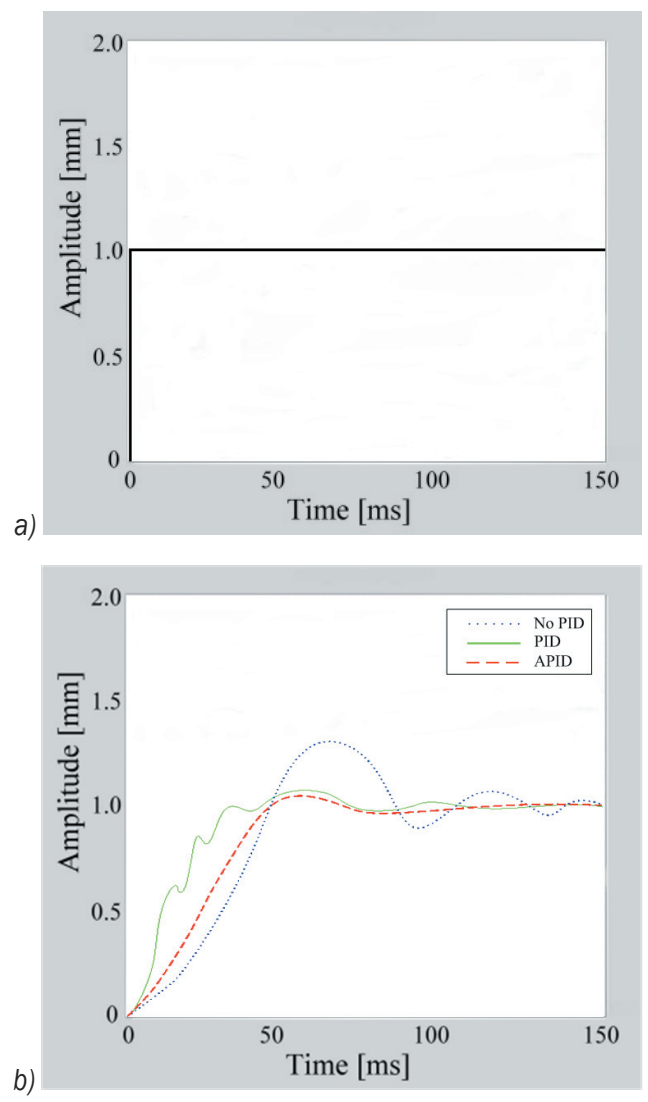

Fig. 9. The experimental results;

a) Input signal, b) Step response signals

time passed. The thickness change with conventional PID is about $0.30 \mathrm{~mm}$, far above the value of APID. Consequently, the improved step response test model by using APID link can reduce the settling time and the overshoot, and thus enhance the surface quality of steel sheet in the HAGC system. This indicates 
the improved step response model is valid, and the experimental results are consistent with the simulated results.
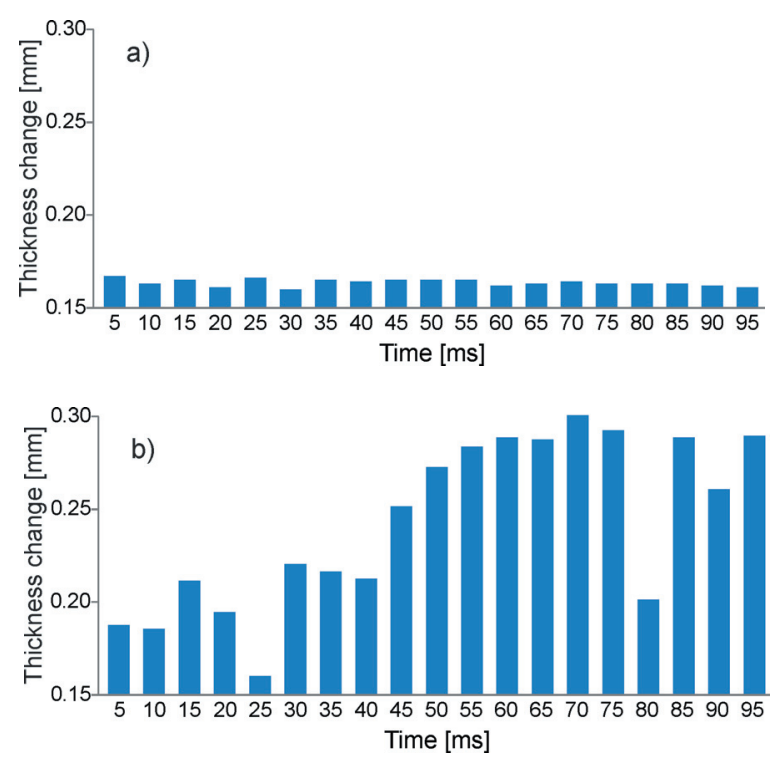

Fig. 10. The measured thickness change of steel sheet; a) with APID, b) with conventional PID

\section{CONCLUSIONS}

In the process of the step response test of HAGC, it is difficult to balance the stability and the flexibility of the system. To improve the control performance of the system, the approach of adding proper link to compensate for the input signal is valid. By adding a PID link, the settling time, and the overshoot can be reduced. However, the conventional PID algorithm also leads to jitters of HAGC at start-up phase. In this paper, based on the established step response test model, the APID link by using BPNN is proposed to improve steel sheet quality. The simulated and experimental results show that the designed step response model with the APID link is useful for overcoming jitters, reducing overshoot and settling time, and accelerating the dynamic response of the HAGC system. Further research to analyse the step response influence of the other components in HAGC systems, such as hydraulic pipes and hydraulic pumps, should be carried out.

\section{ACKNOWLEDGMENT}

This work is supported by the National Natural Science Foundation (Granted No: 51071077), China. The author also gratefully acknowledges the helpful comments and suggestions of the reviewers, which have improved the presentation.

\section{REFERENCES}

[1] Wang, Z., Sun, Y., Peng, K. (2006). Real-time simulator of an AGC system for hot-rolling mill. Journal of University of Science and Technology Beijing, vol. 28, no. 2, p. 171-174, D0l:10.3321/j.issn:1001-053X.2006.02.016. (in Chinese)

[2] Taleb, R., Meroufel, A., Massoum, A. (2014). Control of a uniform step asymmetrical 13-level inverter using particle swarm optimization. Automatika, vol. 55, no. 1, p. 79-89, D0l:10.7305/automatika.2014.01.117.

[3] Gao, Q.M., Li, J.F., Zhao, G.Q. (2010). Modeling and simulation of hydraulic AGC system for $1100 \mathrm{~mm}$ cold rolling mill. Applied Mechanics and Materials, vol. 34-35, p. 523-526, D0l:10.4028/www.scientific.net/AMM.34-35.523.

[4] Tsay T.S. (2007). Analysis and design of feedback control systems with tracking errors square. Asian Journal of Control, vol. 9, no. 3, p.333-339, D0l:10.1111/j.1934-6093.2007. tb00419.x.

[5] Ang, K.H., Chong, G., Li, Y. (2005). PID control system analysis, design, and technology. IEEE Transactions on Control Systems Technology, vol.13, no.4, p. 559-576, Dol:10.1109/ TCST.2005.847331.

[6] Mitsantisuk, C., Nandayapa, M., Ohishi, K., Katsura, S. (2013). Design for sensorless force control of flexible robot by using resonance ratio control based on coefficient diagram method. Automatika, vol. 54, no. 1, p. 62-73, D0l:10.7305/ automatika.54-1.311.

[7] Zhang, Y., Shieh, L.-S., Liu, C.R., Guo, S.M. (2004). Digital PID controller design for multivariable analogue systems with computational input-delay. IMA Journal of Mathematical Control and Information, vol. 21, no. 4, p. 433-456, DOI:10.1093/imamci/21.4.433.

[8] Dou, X., Guo, Q. (2008). Precise digital control system of a moving mirror's reciprocating move at even speed. Journal of Control Theory and Applications, vol. 6, no. 4, p. 431-434, DOI:10.1007/s11768-008-6159-2.

[9] Chang, P.H., Jung, J.H. (2009). A systematic method for gain selection of robust PID control for nonlinear plants of secondorder controller canonical form. IEEE Transactions on Control Systems Technology, vol. 17, no. 2, p. 473-483, D0I:10.1109/ TCST.2008.2000989.

[10] Khosravi, S., Afshar, A., Barazandeh, F. (2011). Design of a novel fuzzy adaptive PI controller for monitor hydraulic AGC system of cold rolling mill. $2^{\text {nd }}$ International Conference on Instrumentation Control and Automation, p. 53-58, D0I:10.1109/ICA.2011.6130129.

[11] Song, X.Y., Yang, Q.J., Zhang, X.M., Feng, Q.G. (2009). Application of compound PID control in the DC servo motor. Applied Mechanics and Materials, vol. 16-19, p. 145-149, DOl:10.4028/www.scientific.net/AMM.16-19.145.

[12] Wan, Y., Wu, C. (2012). Research on open-loop control dynamic characteristics of EHP controlled system based on compound model. Advanced Science Letters, vol. 6, no. 1, p. 257-260, DOI:10.1166/asl.2012.2269. 
[13] Kasprzyczak, L., Macha, E. (2008). Selection of settings of the PID controller by automatic tuning at the control system of the hydraulic fatigue stand. Mechanical Systems and Signal Processing, vol. 22, no. 6, p. 1274-1288, D0l:10.1016/j. ymssp.2007.08.014.

[14] Iruthayarajan, M.W., Baskar, S. (2009). Evolutionary algorithms based design of multivariable PID controller. Expert Systems with Applications, vol. 36, no. 5, p. 9159-9167, Dol:10.1016/j. eswa.2008.12.033.

[15] Ren, X, Du, F., Huang, H., , Yan, H. (2009). Application of fuzzy immune PID control based on PSO in hydraulic AGC press system. International Conference on Intelligent HumanMachine Systems and Cybernetics, p. 427-430, D0l:10.1109/ IHMSC.2009.229.
[16] Sabura Banu, U., Uma, G. (2008). Fuzzy gain scheduled continuous stirred tank reactor with particle swarm optimization based PID control minimizing integral square error. Instrumentation Science and Technology, vol. 36, no. 4, p. 394-409, DOl:10.1080/10739140802151499.

[17] Wang, H., Rong, Y., Liu, S., Cui, J. (2010). Identification for hydraulic AGC system of strip mill based on neural networks. International Conference on Computer Design and Applications, (vol. 2), p. V2-377-V2-380, Dol:10.1109/ ICCDA.2010.5541406.

[18] Sun, M. (2010). Research on generalized predictive control in hydraulic AGC system of cold rolling mill. 2nd International Conference on Intelligent Human-Machine Systems and Cybernetics, p. 159-162, Dol:10.1109/IHMSC.2010.139. 